\title{
Avaliação das Propriedades Físicas, Químicas, Mecânicas e de Superfície de Lâminas de Paricá (Schizolobium amazonicum Huber ex. Ducke)
}

\author{
Rafael Rodolfo de Melo ${ }^{1}$, Cláudio Henrique Soares Del Menezzi², \\ Mário Rabelo de Souza ${ }^{3}$, Diego Martins Stangerlin ${ }^{1}$ \\ ${ }^{1}$ Instituto de Ciências Agrárias e Ambientais, Universidade Federal do Mato Grosso - UFMT, Sinop/MT, Brasil \\ ${ }^{2}$ Engenharia Florestal, Universidade de Brasília - UnB, Brasília/DF, Brasil \\ ${ }^{3}$ Laboratório de Produtos Florestais, Serviço Florestal Brasileiro, Brasília/DF, Brasil
}

\section{RESUMO}

Foi avaliada a qualidade de lâminas produzidas com a madeira de paricá (Schizolobium amazonicum). Para tanto, foram observadas propriedades físicas (massa específica, porosidade, teor de umidade e estabilidade dimensional) e mecânicas (resistência à flexão estática e à tração paralela), realizou-se a avaliação não destrutiva por meio Stress Wave, verificou-se a composição química e a caracterização da superfície (análise de imagem, cor, rugosidade e molhabilidade para ambas as faces das lâminas). Os resultados obtidos indicaram ser as lâminas de paricá um material de coloração branco-acinzentada, baixa massa específica, elevada porosidade, baixa estabilidade dimensional, pouca rugosidade e alta molhabilidade. O módulo de elasticidade dinâmico obtido por Stress Wave e a massa específica apresentaram correlação significativa com o desempenho mecânico das lâminas, podendo ser estes parâmetros utilizados como indicadores de resistência nas estratégias de montagem de compostos laminados.

Palavras-chave: paricá, qualidade de lâminas, propriedades tecnológicas de lâminas.

\section{Evaluation of Physical, Chemical, Mechanical and Surface Properties of the Schizolobium amazonicum Veneer}

\begin{abstract}
The quality of veneer from Schizolobium amazonicum was evaluated assessing physical (density, porosity, moisture content and dimensional stability), mechanical (bending strength and shear strength), nondestructive (stress wave), chemical and surface (image analysis, color, roughness and wettability) properties. The results indicated that the Schizolobium amazonicum veneer presented whitish-gray color, low density, high porosity, low dimensional stability, low roughness and high wettability. The stress wave dynamic modulus of elasticity and veneer density were significantly correlated with the mechanical properties of the veneer. These parameters can be used as indicators for assembling strategies in the manufacturing of laminated composites.
\end{abstract}

Keywords: Schizolobium amazonicum, veneer quality, veneer technological properties. 


\section{INTRODUÇÃO}

A qualidade das lâminas é fundamental tanto para sua performance como para o desempenho de painéis à base de madeira que as utilizem, como é o caso do compensado, do LVL e demais painéis laminados (Ross et al., 1999). Segundo Wang et al. (2001), as propriedades das lâminas que afetam significativamente a qualidade desses produtos podem ser classificadas em dois grupos, conforme a sua origem: i) relacionadas à sua manufatura, como ajuste do torno, rugosidade da superfície, variação de espessura e teor de umidade, e ii) relacionadas à variabilidade natural da madeira, como presença de nós, rachaduras, variação de massa específica, ângulo da grã, espécie e espessura dos anéis de crescimento.

As muitas variáveis envolvidas no processo fazem com que a produção de lâminas por meio de tornos desenroladores demande uma série de cuidados. Todavia, a necessidade de uma elevada produtividade muitas vezes entra em conflito com a qualidade, resultando em uma maior frequência de características indesejáveis no material produzido. Para minimizar a ocorrência destas, torna-se necessário buscar as principais causas de sua ocorrência e, com base nessas informações, conciliar na medida do possível uma maior produtividade com a qualidade do material. Na avaliação qualitativa de lâminas, Daoui et al. (2011) sugerem que sejam considerados como principais critérios, além da presença de defeitos, a rugosidade superficial e as variações de espessura. Tais critérios estão relacionados principalmente à qualidade da matériaprima, à eficiência de pré-tratamentos e a um ajuste adequado do torno laminador.

A rugosidade da superfície também apresenta um papel importante na manufatura de painéis laminados, principalmente no que diz respeito à colagem (Dundar et al., 2008). Esta característica depende da estrutura celular e do método de processamento; além disso, está intimamente relacionada com a molhabilidade, pois quanto maior a rugosidade, maior será a hidrofilicidade da superfície (Piao et al., 2010). A exemplo disso, Faust \& Rice (1986) observaram redução de aproximadamente um terço na qualidade da ligação de painéis LVL, ao compararem a utilização de lâminas rugosas com lâminas mais lisas. Lâminas rugosas reduzem o contato entre as camadas, resultando em uma linha de cola menos resistente ou, ainda, necessitam de um maior volume de adesivo para uma colagem satisfatória.

A molhabilidade de lâminas de madeira pode ser utilizada para avaliar a sua aplicabilidade na produção de painéis. Gray (1992) define a molhabilidade como a facilidade e a eficácia com que um líquido pode se espalhar sobre uma superfície sólida. Conhecendose o comportamento desta variável, pode-se melhorar a interação entre a madeira, os produtos de acabamento, e a colagem.

A estabilidade dimensional das lâminas também deve ser considerada no momento de manufatura dos painéis. Lâminas obtidas de lenhos de tração, compressão ou da região próxima à medula podem apresentar contrações e inchamentos elevados, comportamentos esses que podem ser repassados para os painéis. Por outro lado, lâminas de espécies diferentes podem ser utilizadas de forma conjunta na manufatura de painéis, desde que apresentem, dentre outras características, inchamento e contrações semelhantes (Almeida et al., 2004).

Destaca-se ainda como importante critério qualitativo, a aparência das lâminas, principalmente daquelas que serão utilizadas nas faces dos painéis. Lâminas de melhor aparência podem custar de 1,5 a 6 vezes mais (Melo, 2012). Na análise da qualidade visual das lâminas, a disposição da grã e a ausência de defeitos (Wang et al., 2001; Daoui et al., 2011), e a sua coloração (Iamtasna et al., 2010; Arruda et al., 2011) são os principais parâmetros a serem considerados. Para Camargos \& Gonçalez (2001), as características visuais (cor e figura) são os principais parâmetros avaliados para a escolha de madeiras ou de vários produtos à base de madeira; com base nessas características, geralmente são formulados padrões comerciais, tais como "padrão mogno" e "padrão cerejeira", entre outros. Nesse contexto, foram avaliadas as propriedades físicas, químicas, mecânicas e de superfície das lâminas produzidas a partir da madeira de paricá (Schizolobium amazonicum Huber ex. Ducke). 


\section{MATERIAL E MÉTODOS}

Para a realização dos estudos, foram utilizadas lâminas de paricá (Schizolobium amazonicum) obtidas em uma laminadora localizada no município de Dom Eliseu, Estado do Pará. As toras utilizadas para produção das lâminas foram obtidas de árvores com idade entre cinco e sete anos, oriundas de plantios homogêneos implantados na região de Paragominas-PA. Foram selecionadas lâminas com total ausência de defeitos e conduzidas à câmara climática ( $65 \%$ de umidade relativa e temperatura de $20^{\circ} \mathrm{C}$ ), na qual permaneceram até atingir massa constante - teor de umidade de equilíbrio em torno de $12 \%$

\subsection{Propriedades físicas das lâminas}

Um dos parâmetros utilizados para qualificar as lâminas de paricá foi a sua estabilidade dimensional. Das lâminas selecionadas, foram retiradas aleatoriamente 32 amostras isentas de defeitos, com $0,22 \mathrm{~cm} \times 4 \mathrm{~cm} \times 50 \mathrm{~cm}$ (espessura $\times$ largura $\times$ comprimento). A massa de cada amostra foi obtida e foram marcados pontos específicos nos quais foram tomadas as medições de largura, espessura e comprimento. Posteriormente, estas amostras foram saturadas e tiveram suas dimensões e massas retomadas, procedimento que se repetiu após uma nova estabilização das amostras em câmara climática. Os dados obtidos foram utilizados para determinações da massa específica, da porosidade (relação entre as massas específicas das lâminas e da parede celular $-1,54 \mathrm{~g} / \mathrm{cm}^{3}$ ), do teor de umidade de equilíbrio, das retrações lineares (longitudinal, radial e tangencial) e volumétrica, e do fator anisotrópico, conforme metodologia sugerida pela Comissão PanAmericana de Normas Técnicas - COPANT (1972) e adaptada para lâminas de madeira por Bortoletto Júnior et al. (2000).

\subsection{Propriedades de superfície das lâminas}

As propriedades de superfície foram avaliadas segundo a análise de imagem, cor, rugosidade e molhabilidade. Para tanto, foram utilizadas 60 amostras com as dimensões de $0,22 \mathrm{~cm} \times 4 \mathrm{~cm} \times$ $4 \mathrm{~cm}$ (espessura $\times$ largura $\times$ comprimento), com a obtenção de resultados relativos a ambas as faces das lâminas - superfície interna, na qual ocorre "ataque" da faca na fase de laminação, e superfície externa.

Análise de imagem - foram obtidas imagens com um aumento de $80 \times$ das superfícies das lâminas. A captação das imagens foi realizada com o auxílio de uma câmara modelo AxioCam MRc5 de 5 megapixels acoplada ao estereomicroscópio trinocular modelo 2000 C, ambos da marca Carl Zeiss.

$\begin{array}{rlrrr}\text { Colorimetria } & - & \text { foi } & \text { utilizada a } & \text { técnica } \\ \text { de } & \text { reflectância } & \text { difusa } & \text { no intervalo } & \text { visível }\end{array}$ do espectro eletromagnético, denominada espectrofotocolorimetria. Foi empregado o aparelho Color Eye XTH-X-RITE acoplado a um microcomputador. Para cada amostra, foram tomadas três leituras dos parâmetros colorimétricos em ambos os lados. Antes do início dos ensaios, foi feita a calibração de cores de referências fornecidas pelo equipamento (branco total, com $\mathrm{L}^{\star}=100$, e

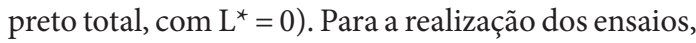
foi utilizado o iluminante D65, composto de uma lâmpada de xenônio, o qual simula a radiação solar diurna, com um ângulo de observação de $10^{\circ}$, em temperatura ambiente. A metodologia adotada para a determinação dos parâmetros colorimétricos $-\mathrm{L}^{*}$ (claridade), coordenadas $\mathrm{a}^{*}$ e $\mathrm{b}^{*}, \mathrm{C}$ (saturação) e $\mathrm{h}^{*}$ (ângulo de tinta) - foi o sistema CIELAB1976, conforme citado por Camargos \& Gonçalez (2001). Os parâmetros $L^{*}, a^{*}, b^{*}, h^{*}$ e $C$ foram obtidos diretamente pelo espectrofotocolorímetro.

Rugosidade - foram realizadas medições na superfície das amostras transversalmente às fibras, utilizando-se o equipamento Surftest SJ - 400 (Mitutoyo), de acordo com a norma JIS B 0601 (JIS, 2001), com cut-off de $0,8 \mathrm{~mm}$ e percurso de avaliação de $8 \mathrm{~mm}$. Os parâmetros avaliados foram: $\mathrm{R}_{\mathrm{a}}$ (média aritmética dos desvios do perfil da linha média), $\mathrm{R}_{z}$ (soma da altura média dos cinco picos mais altos e da profundidade dos cinco vales mais profundos, medidos de uma linha paralela à linha média) e $\mathrm{R}_{t}$ (soma da altura do pico máximo e a profundidade do vale máximo).

Molhabilidade - foi avaliada por meio de medições do ângulo de contato da gota séssil com o uso do Goniômetro - Krüss DSA30 e do software DSA30. Foram utilizados dois líquidos: água destilada e o adesivo fenólico CR-7010 (SI GroupCrios), o qual foi diluído a $5 \%$ com água destilada até atingir a 
viscosidade requerida para medição (menos de 400 cP). O volume da gota depositada sobre o material foi de $15 \mu \mathrm{L}$ e as medições foram realizadas a cada um segundo, por um período de 60 segundos. O ângulo de contato foi tomado aos 30 segundos após a deposição da gota $(\theta)$, sendo definido com base nas análises do tempo médio necessário para a total absorção da gota pela madeira para ambos os líquidos.

\subsection{Propriedades químicas}

A caracterização da composição química foi realizada a partir de amostras retiradas aleatoriamente das lâminas. Os corpos de prova de $2,5 \mathrm{~cm} \times 2,5 \mathrm{~cm}$ $\times 0,22 \mathrm{~cm}$ (largura $\times$ comprimento $\times$ espessura) foram transformados em palitos e, posteriormente, convertidos em serragem, ao empregar moinho de facas do tipo Willey. Subsequentemente, o material moído foi subdividido em três frações granulométricas: abaixo de 40 mesh, entre 40 e 60 mesh e acima de 60 mesh, conforme a norma NBR 14660 (ABNT, 2003b). A partir da fração retida entre as peneiras de 60 e 40 mesh, foram realizadas as análises químicas, em triplicata, por via úmida, para determinação do teor de extrativos, do teor de lignina e do teor de cinzas, conforme as normas NBR 14853, NBR 7989 e NBR 13999 (ABNT, 2003c, d, a), respectivamente. Em relação ao teor de holocelulose, o mesmo foi definido como sendo a diferença entre a composição química total e a composição da fração não carboidrato.

\subsection{Propriedades mecânicas das lâminas}

Para realização dos ensaios mecânicos, foram utilizadas 36 amostras $0,22 \mathrm{~cm} \times 3,6 \mathrm{~cm} \times 40 \mathrm{~cm}$ (espessura $\times$ largura $\times$ comprimento) e, destas, obteve-se o módulo de elasticidade dinâmico por meio do Stress Wave Time. Em seguida, as amostras foram subdivididas ao meio $(0,22 \mathrm{~mm} \times 3,6 \mathrm{~cm} \times$ $20 \mathrm{~cm}$ ), sendo metade destas destinadas ao ensaio de flexão e outra metade ao ensaio de tração paralela às fibras. Os ensaios foram realizados com base na norma COPANT (1972), com adaptações às especificidades das amostras disponíveis. Para o ensaio de tração, a largura das amostras em sua parte central foi reduzida para $1,8 \mathrm{~cm}$ e o ensaio foi conduzido à velocidade de $0,6 \mathrm{~mm} / \mathrm{min}$. No ensaio de flexão, foi utilizado um vão de $12 \mathrm{~cm}$ e velocidade de carregamento de $1,8 \mathrm{~mm} / \mathrm{min}$.

\subsection{Análise dos resultados}

Para os ensaios de molhabilidade, foi avaliada a variabilidade do ângulo de contato por meio do delineamento inteiramente casualizado com arranjo fatorial. Os fatores avaliados foram: líquido utilizado com dois níveis (água e fenol-formaldeído) e face da lâmina, também com dois níveis (interna e externa). Para os fatores e interações detectados como significativos pelo teste de $\mathrm{F}(\mathrm{p}<0,05)$, foi realizada a comparação de médias pelo teste de Skott-Knott $(\mathrm{p}<0,05)$.

Os demais parâmetros estudados (análise visual, análise colorimétrica, estabilidade dimensional, rugosidade e caracterização mecânica) foram avaliados por meio de estatística descritiva (valores mínimo, médio e máximo, e variabilidade). Foram realizadas ainda análises de correlação linear separadamente para os parâmetros relacionados às propriedades físicas, mecânicas e de superfície.

\section{RESULTADOS E DISCUSSÃO}

\subsection{Análise de imagens}

Nas imagens obtidas por meio de estereomicroscópio (Figura 1), fica evidente a maior ocorrência de fendas de laminação em uma das faces das lâminas, especificamente a face interna, na qual ocorre o ataque da faca para produção das lâminas. Conforme mencionado por Suchsland \& Jankowski (1978), o aparecimento dessas fendas na face interna das lâminas é comum durante o processo de laminação em torno desenrolador e sua causa pode ser atribuída à pressão proporcionada na parte interior das lâminas. Desse modo, a utilização de uma compressão adequada da barra de pressão sobre a madeira pode minimizar consideravelmente o aparecimento dessas fendas.

Os parâmetros colorimétricos obtidos para lâminas de paricá podem ser observados na Tabela 1. Considerando-se o agrupamento dos parâmetros colorimétricos sugeridos por Camargos \& Gonçalez (2001), a cor observada para as lâminas 

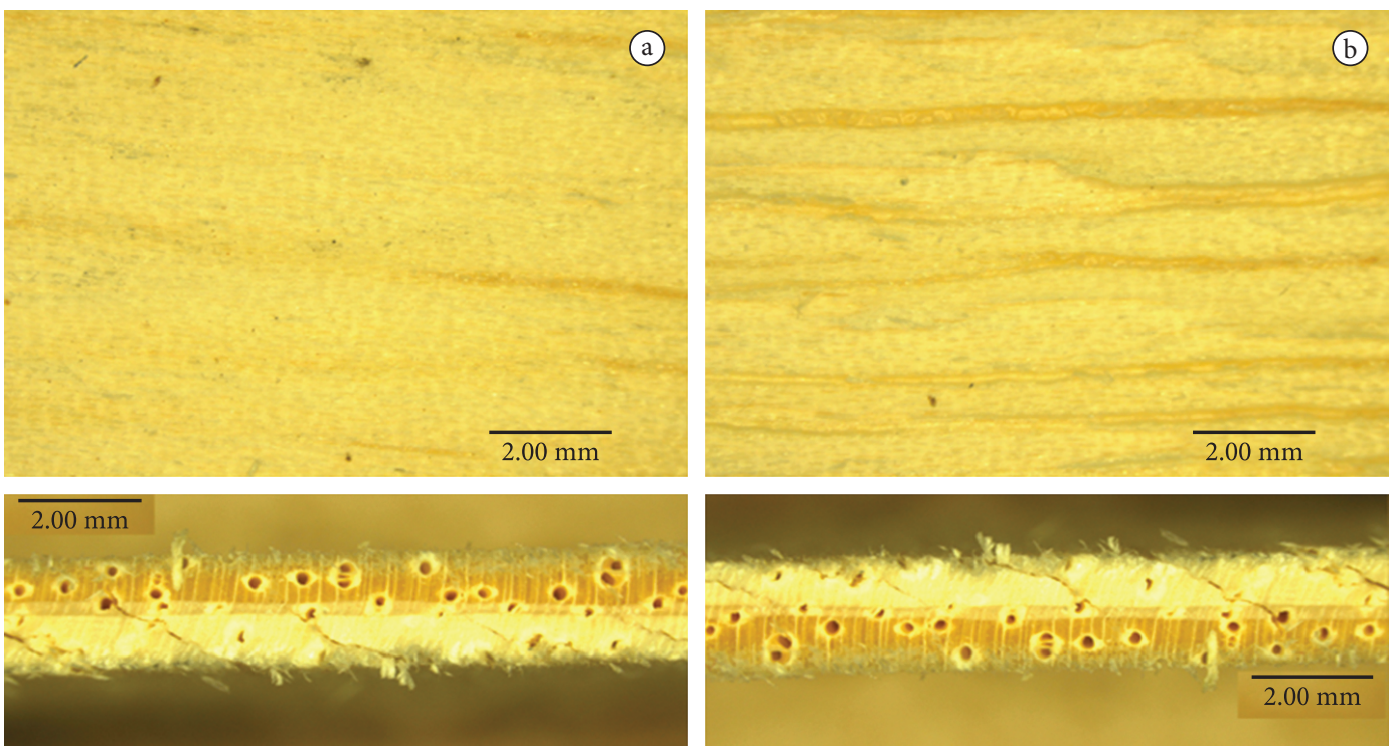

Figura 1. Imagens das superfícies - externa (a) e interna (b), e das bordas das lâminas de paricá.

Figure 1.Surfaces images - external (a) and internal (b) and the edges of Schizolobium amazonicum veneer.

Tabela 1. Parâmetros colorimétricos observados para as lâminas de paricá.

Table 1. Colorimetric parameters observed for Schizolobium amazonicum veneer.

\begin{tabular}{lccccc}
\multicolumn{1}{c}{ Valores } & $\mathbf{L}^{*}$ & $\mathbf{a}^{*}$ & $\mathbf{b}^{*}$ & $\mathbf{C}$ & $\mathbf{h}^{*}$ \\
Máximo & 89,64 & 1,59 & 35,16 & 35,16 & 93,23 \\
Médio & 87,51 & $-0,30$ & 27,56 & 27,57 & 90,68 \\
Mínimo & 83,02 & $-1,32$ & 21,16 & 21,17 & 87,28 \\
\hline $\mathrm{CV}(\%)$ & 1,27 & 92,11 & 11,60 & 11,60 & 1,33 \\
\hline
\end{tabular}

$\mathrm{L}^{*}, \mathrm{a}^{*}, \mathrm{~b}^{*}, \mathrm{C}^{*} \mathrm{e} \mathrm{h}^{*}=$ parâmetros colorimétricos.

de paricá foi branco-acinzentada, característica obtida principalmente pela alta claridade $\left(\mathrm{L}^{*}\right)$, pela presença marcante do pigmento amarelo e pela baixa presença do pigmento vermelho. $\mathrm{O}$ ângulo de tinta elevado $\left(h^{\star}\right)$ posiciona a cor, desta madeira, próxima ao eixo $b^{*}$, confirmando a grande influência da coordenada $b^{*}$ na caracterização da cor da madeira estudada. Resultados similares foram observados por Arruda et al. (2011) para a mesma espécie. Quase todos os valores obtidos por aqueles autores foram similares aos deste estudo, com exceção para o valor da coordenada $a^{\star}$, que foi inferior no presente trabalho. Segundo Mori et al. (2005), o padrão de coloração de uma madeira pode variar em tonalidades que vão desde o bege claro até o marrom escuro, quase preto; dentro destas variações, podem ser encontradas madeiras amareladas, avermelhadas, arroxeadas e alaranjadas.
A combinação entre os elevados valores observados para a coordenada $L^{*}$ e os baixos valores observados para a coordenada $a^{\star}$ pode ser um indicativo do baixo percentual de extrativos presentes na madeira. Ressalta-se ainda que, isoladamente, um baixo valor da coordenada $\mathrm{L}^{*}$ pode ser um indicativo de que a espécie apresenta uma baixa massa específica. A cor da madeira deriva da composição química das substâncias extrativas presentes no xilema - taninos, fenóis, flavonoides, estilbenos, quinonas e outros - que conferem cores diferenciadas ao lenho.

Não foram observadas correlações significativas entre a massa específica e os parâmetros colorimétricos (Tabela 2), o que pode ser atribuído a uma elevada homogeneidade na cor das amostras avaliadas. Os demais parâmetros analisados apresentaram correlações significativas entre si, com as maiores correlações observadas para interações 
entre: a coordenada $b^{*}$ e a saturação $(C)(r=0,99)$; a coordenada $\mathrm{a}^{\star}$ e o ângulo de tinta $\left(\mathrm{h}^{*}\right)(\mathrm{r}=0,97)$, e a claridade $\left(\mathrm{L}^{\star}\right)$ e o ângulo de tinta $(\mathrm{r}=0,67)$.

\subsection{Propriedades químicas}

Os resultados obtidos dos parâmetros químicos das lâminas de paricá podem ser observados na Tabela 3. Os teores de lignina e de cinzas observados foram similares aos verificados por Vidaurre (2010). Já para os teores de extrativos, utilizandose metodologia semelhante à da autora, ao estudar indivíduos de 5 a 11 anos, observaram-se valores inferiores a $3 \%$, enquanto no presente trabalho a média foi de 5,3\%. Apesar da diferença, para ambos os estudos, o teor de extrativos pode ser considerado baixo, em se tratando de uma espécie nativa tropical (Paes et al., 2009).

A baixa concentração de extrativos no paricá pode ser atribuída ao uso de indivíduos jovens e ainda sem a presença de cerne, já que reconhecidamente é nessa região em que se encontram as maiores quantidades de extrativos (Rowell, 2005). A composição química da madeira (principalmente o teor de extrativos) é responsável por inúmeras interações com a adsorção e a dessorção de umidade, a retração volumétrica e a molhabilidade (Cruz, 2006). Esses componentes

Tabela 2. Correlações entre a massa específica e os parâmetros colorimétricos.

Table 2. Correlation between density and colorimetric parameters.

\begin{tabular}{|c|c|c|c|c|c|}
\hline & $\mathbf{L}^{*}$ & $\mathbf{a}^{*}$ & $\mathbf{b}^{*}$ & C & $\mathbf{h}^{*}$ \\
\hline $\mathrm{P}$ & $-0,03^{\mathrm{NS}}$ & $0,11^{\mathrm{NS}}$ & $0,14^{\mathrm{NS}}$ & $0,14^{\mathrm{NS}}$ & $-0,10^{\mathrm{NS}}$ \\
\hline $\mathrm{L}^{*}$ & & $-0,64^{\star *}$ & $-0,56^{\star \star}$ & $-0,56^{\star *}$ & $0,67^{\star *}$ \\
\hline$a^{*}$ & & & $0,22^{\star}$ & $0,22^{*}$ & $-0,99^{\star *}$ \\
\hline $\mathrm{b}^{*}$ & & & & $0,99^{* *}$ & $-0,26^{* *}$ \\
\hline $\mathrm{C}$ & & & & & $0,26^{\star *}$ \\
\hline
\end{tabular}

Tabela 3. Parâmetros químicos observados para as lâminas de paricá.

Table 3. Chemical parameters observed for Schizolobium amazonicum veneer.

Holocelulose Lignina Extrativos Cinzas

ocupam uma parte do espaço da parede celular que, normalmente, seria ocupada pela água; logo, sua existência pode deixar madeiras mais ou menos permeáveis.

Paes et al. (2009), ao estudarem algumas espécies nativas, verificaram teores extrativos superiores a $10 \%$, como foram os casos da Myracrodruon urundeuva (14,34\%), da Amburana cearenses (18,02\%) e do Schinopsis brasiliensis $(21,46 \%)$. O baixo teor de extrativos apresentado pela madeira de paricá, quando comparado a outras espécies tropicais, em contrapartida, pode favorecer o processo de colagem de lâminas, pois a presença deles pode interferir na polimerização da resina. Entretanto, no presente estudo, não foram identificados quais são os extrativos, mas apenas a participação percentual destes na composição da madeira (Vidaurre, 2010). Logo, a existência de alguma classe de extrativo que possa interferir no processo de colagem, mesmo que em pequenas concentrações, não deve ser descartada.

A composição química da madeira está intimamente relacionada com sua utilização. Determinadas características, como adequabilidade para a produção de papel, durabilidade natural, trabalhabilidade, cor, resistência mecânica, higroscopicidade, poder energético e grande parte das características físico-mecânicas da madeira, são mais ou menos influenciadas pela qualidade e pela proporção relativa dos diferentes componentes químicos de sua estrutura (Rowell, 2005). Apenas a partir das características desses componentes e o papel que cada um deles exerce, é possível dar à madeira a utilização mais conveniente, explorando todo o seu potencial.

\subsection{Propriedades físicas das lâminas}

As lâminas de paricá avaliadas apresentaram baixa massa específica, elevada porosidade e, consequentemente, alta capacidade de absorção de água. Os valores de retratibilidade tangencial e volumétrica observados para as lâminas de paricá (Tabela 4) foram próximos aos observados por Bortoletto Júnior \& Belini (2002) para lâminas de Schizolobium parahyba. Já para retrações radiais e o coeficiente anisotrópico, os resultados do presente estudo foram menores. O Laboratório de Produtos Florestais (LPF, 2012) apresenta como valores de 
referência para madeira de paricá 5,1\%, 4,3\%, 11,1\% e 1,2 para contrações tangencial, radial, volumétrica e coeficiente anisotrópico, respectivamente. Contudo, esses resultados foram obtidos para madeira de indivíduos adultos e a partir de blocos de madeira, cuja forma e dimensões utilizadas para os ensaios são absolutamente diferentes da forma e das dimensões das amostras de lâminas avaliadas neste trabalho.

Ainda na Tabela 4, observa-se que as retrações longitudinal e radial, e o coeficiente anisotrópico apresentaram elevado coeficiente de variação. Essa variabilidade nos resultados pode ser atribuída à utilização de lâminas de diferentes regiões radiais - externa (próxima à casca) e interna (próxima à medula), características que, reconhecidamente, influenciam a estabilidade dimensional da madeira (Melo et al., 2010).

Almeida et al. (2004) também observaram para lâminas de clones de Eucalyptus grandis $\times$ Eucalyptus urophylla valores de retrações superiores, mas com um coeficiente anisotrópico menor. O elevado coeficiente anisotrópico obtido para a madeira de paricá $(T / R>2)$ indica que as lâminas avaliadas são consideravelmente instáveis. Todavia, isoladamente, esse aspecto não pode ser considerado limitante para seu uso, tendo em vista as inúmeras técnicas existentes que visam a melhorar a estabilidade de madeiras e painéis de madeiras, como tratamentos termomecânicos, alteração química, laminação cruzada, preenchimento e revestimento, dentre outras.

Para Bortoletto Júnior et al. (2000), o conhecimento da retratibilidade de lâminas é fundamental na manufatura de painéis laminados. Segundo esses autores, até mesmo lâminas de espécies diferentes podem ser utilizadas para produzir painéis sem que sua qualidade seja prejudicada, desde que, em seu processo de manufatura, sejam produzidas lâminas que apresentem, dentre outras características, desempenhos físico e mecânico similares. Tal aspecto possibilitaria um maior aproveitamento da matéria-prima, além de uma maior flexibilidade na escolha desta para produção industrial.

Os parâmetros 'massa específica', 'porosidade' e 'teor de umidade de equilíbrio' observados para as lâminas de paricá não se correlacionaram com os índices (retratibilidade longitudinal, radial, tangencial e volumétrica) utilizados para quantificar a estabilidade dimensional (Tabela 5). O maior

Tabela 4. Propriedades físicas observadas para as lâminas de paricá.

Table 4. Physical properties observed for Schizolobium amazonicum veneer.

\begin{tabular}{lcccccrrrrr}
\multicolumn{1}{c}{ Valores } & TUeq & $\boldsymbol{\Phi}$ & $\boldsymbol{\rho}$ & $\mathbf{L g}$ & $\mathbf{R d}$ & $\mathbf{T g}$ & $\mathbf{R v}$ & T/R \\
\hline Máximo & 14,32 & 72,08 & 0,43 & 0,80 & 6,20 & 9,02 & 13,74 & 5,60 & \\
Médio & 12,68 & 79,22 & 0,32 & 0,42 & 3,17 & 7,24 & 10,55 & 2,94 \\
Mínimo & 11,31 & 82,47 & 0,27 & 0,20 & 1,16 & 5,56 & 7,55 & 1,12 \\
CV(\%) & 7,02 & 15,67 & 12,50 & 40,48 & 50,16 & 11,19 & 17,81 & 50,68 \\
\hline
\end{tabular}

TUeq = teor de umidade de equilíbrio; $\Phi$ = porosidade; $\rho$ = massa específica; $\mathrm{Lg}$, Rd e Tg = retratibilidade linear longitudinal, radial e tangencial; $\mathrm{Rv}=$ retratibilidade volumétrica; $\mathrm{T} / \mathrm{R}=$ coeficiente anisotrópico.

Tabela 5. Correlações entre as propriedades físicas das lâminas de paricá.

Table 5. Correlation between physical properties of the Schizolobium amazonicum veneer.

\begin{tabular}{cccccccc} 
& Tg & Rd & $\mathbf{R v}$ & TUeq & $\boldsymbol{\rho}$ & $\boldsymbol{\Phi}$ & T/R \\
Lg & $0,338^{\mathrm{NS}}$ & $0,173^{\mathrm{NS}}$ & $0,356^{*}$ & $0,180^{\mathrm{NS}}$ & $0,060^{\mathrm{NS}}$ & $-0,048^{\mathrm{NS}}$ & $-0,254^{\mathrm{NS}}$ \\
Tg & & $0,258^{\mathrm{NS}}$ & $0,654^{* *}$ & $0,110^{\mathrm{NS}}$ & $-0,051^{\mathrm{NS}}$ & $0,047^{\mathrm{NS}}$ & $-0,047^{\mathrm{NS}}$ \\
Rd & & & $0,901^{* *}$ & $-0,141^{\mathrm{NS}}$ & $-0,024^{\mathrm{NS}}$ & $0,036^{\mathrm{NS}}$ & $-0,911^{* *}$ \\
Rv & & & & $-0,050^{\mathrm{NS}}$ & $-0,034^{\mathrm{NS}}$ & $0,042^{\mathrm{NS}}$ & $-0,800^{* *}$ \\
TUeq & & & & & $0,033^{\mathrm{NS}}$ & $-0,060^{\mathrm{NS}}$ & $0,078^{\mathrm{NS}}$ \\
$\rho$ & & & & & & $-0,998^{* *}$ & $-0,217^{\mathrm{NS}}$ \\
$\Phi$ & & & & & & $0,204^{\mathrm{NS}}$ \\
\hline
\end{tabular}

Lg, Rd, Tg e Rv = retratibilidade linear longitudinal, radial e tangencial e retratibilidade volumétrica; TUeq = teor de umidade de equilíbrio; $\rho=$ massa específica básica; $\Phi=$ porosidade; $\mathrm{T} / \mathrm{R}=$ coeficiente anisotrópico; ${ }^{\mathrm{NS}}=$ não significativo; ${ }^{* *} \mathrm{e}^{*}=$ significativos nos níveis de $1 \%$ e $5 \%$, respectivamente. 
número de correlações significativas foi observado para retratibilidade volumétrica $(\mathrm{Rv})$, que obteve quatro correlações de sete possíveis, com destaque para correlações de 0,90 com a retratibilidade radial (Rd) e de 0,80 com o coeficiente anisotrópico (T/R). No geral, os valores de retratibilidade lineares, volumétrica e o coeficiente anisotrópico apresentaram correlação significativa apenas entre os mesmos.

Ainda na Tabela 5, é visto que o teor de umidade saturado obteve correlação significativa negativa com a massa específica. Segundo Melo et al. (2010), isso se explica por ser a massa específica uma medida de quantidade de parede celular presente em uma determinada espécie de madeira. Os mesmos autores esclarecem ainda que, sendo a massa específica da parede celular aproximadamente constante, independentemente da espécie florestal, a porosidade da madeira será o principal determinante desta variável. Isso significa que quanto maior o volume de espaços vazios (poros), menor será a massa específica e vice-versa, o que, consequentemente, promoveu maiores teores de umidade nas amostras de menores massas específicas.

\subsection{Análise da superfície - rugosidade e molhabilidade}

Foram observadas variações significativas entre os parâmetros de rugosidade para face externa e face interna das lâminas. A média dos desvios do perfil $\left(R_{a}\right)$, a soma dos cinco menores com os cinco maiores picos $\left(R_{z}\right)$ e a soma do maior pico com o maior vale $\left(R_{t}\right)$ foram superiores para face interna das lâminas (Tabela 6). Esse comportamento é tido como padrão

Tabela 6. Parâmetros de rugosidade das faces externa e interna das lâminas.

Table 6. Roughness parameters of the external and internal the veneer surface.

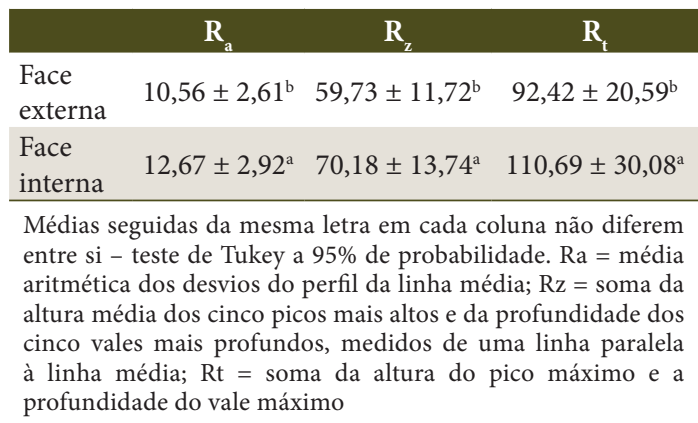

para lâminas produzidas em tornos desenroladores e, segundo Suchsland \& Jankowsky (1978), é ocasionado pela pressão e pelo flexionamento exercido sob a parte interna da lâmina.

Arruda (2012) verificou resultados semelhantes para lâminas produzidas com amescla (Trattinnickia burseraefolia), assim como Daoui et al. (2011), para lâminas de beech (Fagus sylvatica), em que a face externa das lâminas apresentou menor rugosidade. Em média, os valores de rugosidade observados para o paricá foram inferiores aos observados para o Fagus sp. (Bekhta \& Marutzky, 2007) e a Trattinnickia burseraefolia (Arruda, 2012).

Uma menor rugosidade é desejável para produção de painéis laminados, por possibilitar um íntimo contato entre as peças, proporcionando uma melhor aderência entre as lâminas, o que, por sua vez, aumenta a resistência da linha de cola (Piao et al., 2010). Tal aspecto faz com que a rugosidade seja um dos principais parâmetros utilizados para avaliar a qualidade de lâminas (Dundar et al., 2008). Entretanto, vale ressaltar que a rugosidade das lâminas não pode ser considerada limitante para produção de painéis, tendo em vista a existência de técnicas que objetivam sua redução (Tanritanir et al., 2006; Bekhta \& Marutzky, 2007; Arruda, 2012).

A massa específica das lâminas apresentou correlação negativa e significativa para todos os parâmetros de rugosidade, evidenciando haver uma tendência de redução da rugosidade com o aumento da massa específica (Tabela 7). Esse comportamento também foi verificado por Cruz (2006) e pode ser explicado por uma maior resistência das fibras ao ataque da faca do torno desenrolador no processo de manufatura das lâminas, o que proporciona um menor aparecimento de fissuras. $\mathrm{O} \mathrm{R}_{\mathrm{a}}$ foi o parâmetro

Tabela 7. Correlações entre a massa especifica e os parâmetros de rugosidade.

Table 7. Correlation between density and roughness parameters.

\begin{tabular}{rrrr} 
& $\mathbf{R}_{\mathrm{a}}$ & $\mathbf{R}_{\mathbf{z}}$ & $\mathbf{R}_{\mathbf{t}}$ \\
$\rho$ & $-0,366^{* *}$ & $-0,184^{*}$ & $-0,190^{*}$ \\
$\mathrm{R}_{\mathrm{a}}$ & & $0,854^{* *}$ & $0,699^{* *}$ \\
$\mathrm{R}_{\mathrm{z}}$ & & & $0,838^{* *}$ \\
\hline
\end{tabular}

$\rho=$ massa específica; $R_{a}, R_{z}$ e $R_{t}=$ parâmetros do ensaio de rugosidade; ${ }^{\mathrm{NS}}=$ não significativo; ${ }^{* *} \mathrm{e}^{*}=$ significativos nos níveis de $1 \%$ e $5 \%$, respectivamente. 
que melhor se correlacionou com a massa específica $(\mathrm{r}=0,37)$. Os demais parâmetros também obtiveram correlações significativas entre si, sendo estas diretas.

Quanto à molhabilidade, para ambos os líquidos analisados, inicialmente o ângulo de contato diminuiu rapidamente (fase de espalhamento), até atingir um ponto de equilíbrio em que a redução se deu de forma mais lenta (fase de difusão) (Figura 2). Em um primeiro contato entre o líquido e a superfície da madeira, há uma maior energia livre da superfície, ocasionando um rápido espalhamento e penetração do líquido. Em razão da alta variabilidade inicial, sugere-se que a análise da molhabilidade se dê com comparações entre ângulos após essa fase.

Uma clara diferenciação entre os ângulos foi observada entre as faces interna e externa das lâminas, quando o líquido utilizado foi a água, com uma redução mais acentuada para a face mais rugosa das lâminas (interna). Quando o líquido utilizado foi o adesivo, os valores dos ângulos para ambas as faces foram similares, exceto no início do ensaio. Logo, a diferença de rugosidade entre as superfícies não influenciou a variação do ângulo, resultado esse que pode ser atribuído a uma maior viscosidade da resina fenol-formaldeído.

A análise de molhabilidade para diferentes faces e adesivos indicou que, quando se utilizou água, o ângulo de contato foi menor que o obtido para o adesivo (Tabela 8). Embora diversos fatores intrínsecos ao substrato (rugosidade, topografia, morfologia e composição química do material) influenciem o grau de molhabilidade, neste estudo esse comportamento pode ser atribuído principalmente à diferença de viscosidade e tensão superficial dos líquidos. Conforme relatado por Cruz (2006), quanto menor for a viscosidade do líquido, mais rapidamente ocorrerá a sua penetração na madeira - fato ocorrido quando o líquido utilizado foi a água.

Com relação à comparação entre as faces, constatou-se diferença significativa apenas quando o líquido utilizado foi a água. Esse resultado corrobora com o observado por Piao et al. (2010), que afirmam que quanto maior a rugosidade, menor o ângulo de contato e, consequentemente, maior a molhabilidade da madeira. No entanto, Gray (1992) destaca haver um limite para esse comportamento, pois, segundo o autor, o excesso de rugosidade na superfície pode oferecer resistência à penetração do adesivo por causa da presença de ar em suas cavidades. Não foi

Tabela 8. Ângulo de contato médio observado para os diferentes líquidos e faces das lâminas.

Table 8. Contact angle average observed for liquids and surfaces evaluated.

\begin{tabular}{lcc} 
Superfície da lâmina & Água & Fenol \\
\hline Face Externa & $1,73^{\mathrm{aB}}$ & $69,38^{\mathrm{aA}}$ \\
\hline Face Interna & $0,00^{\mathrm{bB}}$ & $69,77^{\mathrm{aA}}$ \\
\hline
\end{tabular}

Médias seguidas pela mesma letra, minúscula na coluna e maiúscula na linha, em cada seção, não diferem estatisticamente entre si pelo teste de Scott-Knott a 95\% de probabilidade.
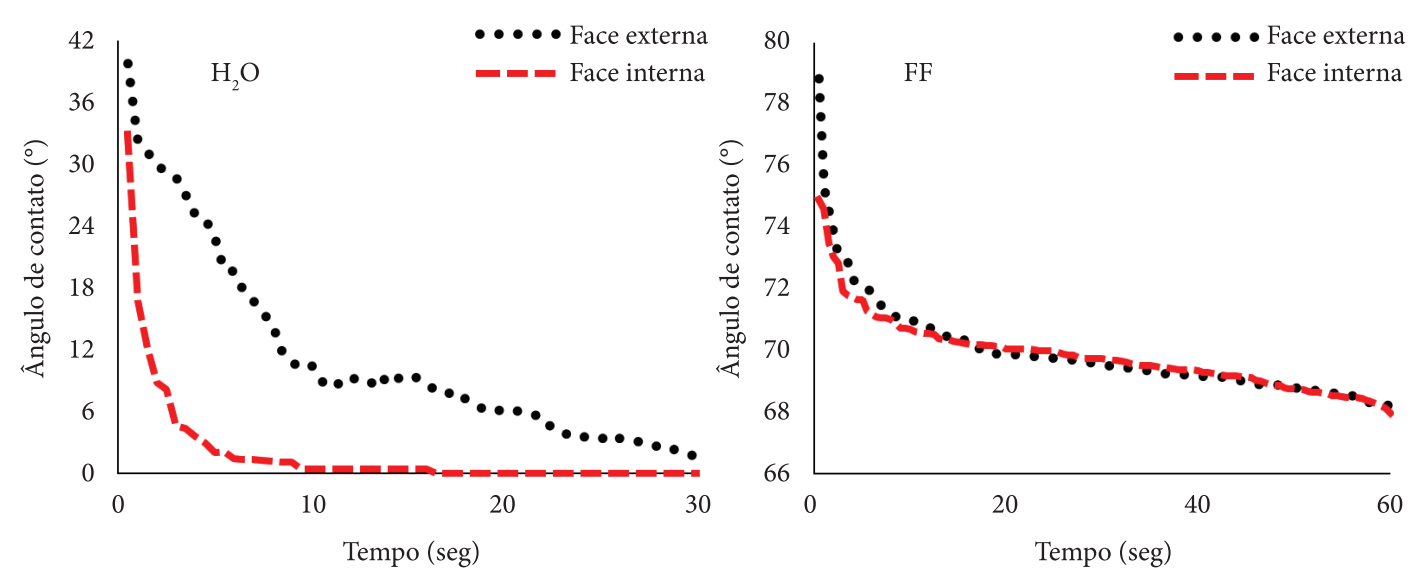

Figura 2. Variação do ângulo de contato em função do tempo para água $\left(\mathrm{H}_{2} \mathrm{O}\right)$ e fenol-formaldeído $(\mathrm{FF})$ nas faces interna e externa das lâminas.

Figure 2. Contact angle variation by time for water $\left(\mathrm{H}_{2} \mathrm{O}\right)$ and phenol-formaldehyde $(\mathrm{FF})$ in internal and external surface veneer. 
constatada correlação significativa entre a massa específica das amostras e o ângulo de contato, para qualquer das faces das lâminas, dos líquidos utilizados ou para o conjunto dos dados.

\subsection{Propriedades mecânicas das lâminas}

Os valores do módulo de elasticidade dinâmico $\left(E_{\mathrm{md}}\right)$ observados para as lâminas de paricá ficaram entre 5.000 a $10.000 \mathrm{MPa}$ (Tabela 9). Diferente disso, Iwakiri et al. (2010) observaram, para lâminas da mesma espécie e com massa específica similar, valores variando entre 3.000 e $6.000 \mathrm{MPa}$. Essa alta variabilidade pode ser atribuída a diversos fatores, seja pelas características genéticas, fenotípicas ou até mesmo silviculturais (Ohashi et al., 2010). A exemplo disso, pode-se destacar a idade em que a árvore é abatida para laminação, a qual pode variar de quatro a sete anos, dependendo da qualidade do sítio ou da demanda do setor industrial.

Para a massa específica, foram observados valores variando entre 0,27 e $0,43 \mathrm{~g} / \mathrm{cm}^{3}$, com distribuição similar à observada para o $E_{\mathrm{md}}$. Os resultados dos ensaios mecânicos e da massa específica podem ser observados na Tabela 9, conjuntamente com valores de massa específica das amostras ensaiadas.
Dentre os parâmetros avaliados, o $E_{\mathrm{md}}$ foi o único que obteve correlação significativa com todas as variáveis analisadas, influenciando diretamente os parâmetros avaliados (Tabela 10). No geral, o aumento da resistência das amostras foi diretamente proporcional ao aumento do $E_{m d}$ e da $\rho$. Estes resultados estão de acordo com autores que afirmam ser o uso de ferramentas com tecnologias acústicas ou da massa específica aceitáveis na predição das propriedades, do controle de qualidade e da classificação das lâminas (Ross et al., 1999; Pellerin \& Ross, 2002; Wang et al., 2001; Lara Palma et al., 2012; Melo, 2012). Tais características possibilitam a utilização dessas variáveis como um indicativo de qualidade das lâminas e, consequentemente, do seu uso para seleção e posicionamento das lâminas no processo de manufatura de painéis laminados.

A velocidade de propagação das ondas pelo Stress Wave apresentou correlação significativa apenas com o $E_{\text {md }}$. Os maiores coeficientes de correlação foram observados entre $E_{\text {md }} \times$ massa específica $(\rho)(0,92)$, módulo de elasticidade $\left(E_{\mathrm{m}}\right) \times$ módulo de ruptura $\left(f_{\mathrm{m}}\right)(0,64), E_{\mathrm{md}} \times f_{\mathrm{m}}(0,63)$ e $\rho \times$ tração paralela às fibras $\left(f_{\mathrm{t}, 0}\right)(0,57)$. Também foi observada correlação significativa entre a resistência em $f_{\mathrm{m}} \times f_{\mathrm{t}, 0}(0,38)$.

Tabela 9. Valores observados para a massa específica e ensaios mecânicos.

Table 9. Observed values of specific gravity and mechanical tests.

\begin{tabular}{lccccc}
\multicolumn{1}{c}{ Valores } & $\rho\left(\mathbf{g} / \mathbf{c m}^{3}\right)$ & $E_{\mathbf{m d}}(\mathbf{M P a})$ & $E_{\mathbf{m}}(\mathbf{M P a})$ & $f_{\mathbf{m}}(\mathbf{M P a})$ & $f_{\mathbf{t}, 0}(\mathbf{M P a})$ \\
Máximo & 0,43 & 9540 & 8830 & 32,19 & 24,74 \\
Média & 0,32 & 7015 & 5975 & 20,63 & 16,84 \\
Mínimo & 0,27 & 5597 & 3271 & 11,06 & 12,63 \\
CV(\%) & 12,26 & 14,32 & 24,80 & 30,21 & 18,30 \\
\hline
\end{tabular}

$\rho=$ massa específica; $E_{\mathrm{md}}=$ módulo de elasticidade dinâmico; $E_{\mathrm{m}}$ e $f_{\mathrm{m}}=$ módulos de elasticidade e ruptura em flexão estática; $f_{\mathrm{t}, 0}=$ tração paralela às fibras.

Tabela 10. Correlações entre as propriedades mecânicas avaliadas.

Table 10. Correlation between mechanical properties evaluated.

\begin{tabular}{cccccc} 
& $\mathbf{V}_{0}$ & $E_{\mathrm{md}}$ & $E_{\mathrm{m}}$ & $f_{\mathrm{m}}$ & $f_{\mathrm{t}, 0}$ \\
$\mathrm{P}$ & $0,158^{\mathrm{NS}}$ & $0,916^{* *}$ & $0,478^{\star *}$ & $0,621^{* *}$ & $0,573^{\star *}$ \\
$\mathrm{~V}_{0}$ & & $0,533^{* *}$ & $0,044^{\mathrm{NS}}$ & $0,239^{\mathrm{NS}}$ & $0,167^{\mathrm{NS}}$ \\
$E_{\mathrm{md}}$ & & $0,418^{*}$ & $0,634^{* *}$ & $0,538^{* *}$ \\
$E_{\mathrm{m}}$ & & & $0,640^{* *}$ & $0,291^{\mathrm{NS}}$ \\
$f_{\mathrm{m}}$ & & & & $0,379^{*}$ \\
\hline
\end{tabular}

$\rho=$ massa específica; $\mathrm{V}_{0}=$ velocidade de propagação das ondas; $E_{\mathrm{md}}=$ módulo de elasticidade dinâmico; $E_{\mathrm{m}}$ e $f_{\mathrm{m}}=$ módulos de

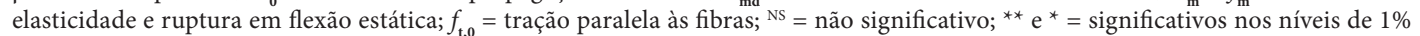
e $5 \%$, respectivamente. 


\section{CONCLUSÕES}

As lâminas da madeira de Schizolobium amazonicum apresentam coloração brancoacinzentada, baixa concentração de extrativos, baixa estabilidade dimensional, pouca rugosidade e alta molhabilidade. A maior presença de fendas de laminação na face interna das lâminas influenciou o grau de molhabilidade à água. Já quando se utilizou o fenol-formoldeído, não foi constatada diferença significativa para o ângulo de contato nas diferentes faces das lâminas. O módulo de elasticidade dinâmico obtido por Stress Wave e a massa específica das lâminas se correlacionam diretamente com o aumento da resistência, podendo ser utilizados com eficácia na classificação e na predição de suas propriedades mecânicas.

\section{AGRADECIMENTOS}

Os autores agradecem ao INCT Madeiras da Amazônia pelo recurso disponibilizado para compra do goniômetro, a empresa Rio Concrem Industrial Limitada pela doação das lâminas e a CAPES pela concessão da bolsa de Doutorado ao primeiro autor.

\section{STATUS DA SUBMISSÃO}

Recebido: 19/09/2012

Aceito: 16/12/2012

Publicado: 30/06/2013

\section{AUTOR(ES) PARA CORRESPONDÊNCIA}

\section{Rafael Rodolfo de Melo}

Instituto de Ciências Agrárias e Ambientais, Universidade Federal do Mato Grosso - UFMT, Sinop, MT, Brasil

e-mail:rrmelo2@yahoo.com.br

\section{REFERÊNCIAS}

Almeida RR, Bortoletto Júnior G, Jankowsky IP. Produção de lâminas a partir de clones do híbrido Eucalyptus grandis $x$ Eucalyptus urophylla. Scientia Forestalis 2004; 32(65): 49-58.

Arruda LM, Gonçalez JC, Del Menezzi CHS, Melo RR. Estudo preliminar das propriedades de compensados produzidos com lâminas de paricá (Schizolobium amazonicum Huber ex Ducke) modificadas termomecanicamente. Ciência da Madeira 2011; 2(1): 29-42.

Arruda LM. Modificação termomecânica da madeira de amescla (Trattinnickia burseraefolia (Mart.) Willd.): efeito sobre as propriedades de lâminas e compensados [dissertação]. Brasília: Faculdade de Tecnologia, Universidade de Brasília; 2012.

Associação Brasileira de Normas Técnicas - ABNT. NBR 13999: Papel, cartão, pastas celulósicas e madeira - Determinação do resíduo (cinza) após a incineração a $525^{\circ} \mathrm{C}$. Rio de Janeiro; $2003 \mathrm{a}$.

Associação Brasileira de Normas Técnicas - ABNT. NBR 14660: Madeira - Amostragem e preparação para análise. Rio de Janeiro; 2003b.

Associação Brasileira de Normas Técnicas - ABNT. NBR 14853: Madeira - Determinação do material solúvel em etanol-tolueno e em diclorometano. Rio de Janeiro; 2003c.

Associação Brasileira de Normas Técnicas - ABNT. NBR 7989: Pastas celulósicas e madeira - Determinação de lignina insolúvel em ácido. Rio de Janeiro; 2003d.

Bekhta P, Marutzky R. Reduction of glue consumption in the plywood production by using previously compressed veneer. European Journal of Wood and Wood Products 2007; 65(1): 87-88. http://dx.doi. org/10.1007/s00107-006-0142-8

Bortoletto Júnior G, Belini UL. Produção de lâminas e manufatura de compensados a partir da madeira de guapuruvu (Schizolobium parayba Blake.) proveniente de um plantio misto de espécies nativas. Cerne 2002; 8(2): 1-16.

Bortoletto Júnior G, Francisco FMLH, Cavalcante MG, Belini UL, Caldas VF. Shrinkage in veneer sheets of Eucalyptus wood. In: Anais da IX Reunión sobre investigación y desarrollo de productos forestales; 2000; Concepción. Concepción: Infor; 2000. p. 95-97.

Camargos JA, Gonçalez JC. A colorimetria aplicada como instrumento na elaboração de uma tabela de cores de madeira. Brasil Florestal 2001; 20(71): 30-41.

Comissão Pan-Americana de Normas Técnicas - COPANT. COPANT 462: Madeiras - método de deternación de lacontracción. Buenos Aires: COPANT; 1972.

Cruz MMS. Estudo da molhabilidade da madeira de pinho pela resina ureia-formaldeído [tese]. Lisboa: Instituto Superior de Agronomia, Universidade Técnica de Lisboa; 2006.

Daoui A, Descamps C, Marchal R, Zerizer A. Influence of veneer quality on beech LVL mechanical properties. Maderas Ciencia y tecnologia 2011; 13(1): 69-83. 
Dundar T, Ayrilmis N, Candan Z. Evaluation of surface roughness of laminated veneer lumber (LVL) made from beech veneers treated with various fire retardants and dried at different temperatures. Forest Products Journal 2008; 58(1-2): 71-76.

Faust TD, Rice JT. Effect of veneer surface roughness on glue bond quality in Southern pine plywood. Forest Products Journal 1986; 36(4): 57-62.

Gray VR. The wettability of wood. Forest Products Journal 1992; 12(9): 452-461.

Iamtasna B, Piyasombatkul T, Prichanont S, Muangnapoh C. Use of hemicellulase in sequence with hydrogen peroxide and laccase for improvement of teak veneer surface color. Journal of Wood Science 2010; 56: 184-188. http://dx.doi.org/10.1007/ s10086-009-1095-4

Iwakiri S, Matos JLM, Pinto JA, Viana LC, Souza MM. Produção de painéis laminados unidirecionais - LVL com lâminas de Schizolobium amazonicum, Eucalyptus saligna e Pinus taeda. Cerne 2010; 16(4): 557-563.

Japanese Industrial Standard - JIS. JIS B 0601: Geometrical Products Specifications (GPS) - Surface texture: Profile method - Terms, definitions and surface texture parameters. Tokyo; 2001.

Laboratório de Produtos Florestais - LPF. Database of Brazilian woods. Brasília: IBAMA; 2012. [cited 2012 abr.]. Available from: http://www.ibama.gov.br/lpf/ madeira

Lara Palma HA, Escobar JF, Ballarin AW, Leonello EC. Influência da qualidade das lâminas no desempenho mecânico à flexão de painéis compensados de Hevea brasiliensis. Floresta e Ambiente 2012; 19(2): 133-140. http://dx.doi.org/10.4322/floram.2012.015

Melo RR, Stangerlin DM, Del Menezzi CHS, Gatto DA, Calegari L. Caracterização física e mecânica da madeira de Araucaria angustifolia (Bertol.) Kuntze. Revista Brasileira de Ciências Agrárias 2010; 5(1): 67-73. http:// dx.doi.org/10.5039/agraria.v5i1a515

Melo RR. Avaliação de variáveis tecnológicas na produção de painéis LVL confeccionados com paricá (Schizolobium amazonicum Huber ex. Ducke) [tese]. Brasília: Faculdade de Tecnologia, Universidade de Brasília; 2012.
Mori CLSO, Lima JT, Mori FA, Trugilho PF, Gonçalez JC. Caracterização da cor da madeira de clones de híbridos de Eucalyptus spp. Cerne 2005; 11(2): 137-146.

Ohashi ST, Yared AG, Farias Neto JT. Variabilidade entre procedências de paricá Schizolobium parahyba var amazonicum (Huber ex Ducke) Barneby plantadas no município de Colares - Pará. Acta Amazônica 2010; 40(1): 81-88. http://dx.doi. org/10.1590/S0044-59672010000100011

Paes JB, Morais VM, Lima CR, Santos GJC. Resistência natural de nove madeiras do semiárido brasileiro a fungos xilófagos em simulares de campo. Revista Árvore 2009; 33(3): 515-520. http://dx.doi.org/10.1590/ S0100-67622009000300013

Pellerin RF, Ross JR. Nondestructive evaluation of wood. Madison: FPS; 2002. PMCid:1876282.

Piao C, Winandy JE, Shupe TF. From hydrophilicity to hydrophobicity: a critical review: Part I. wettability and surface behavior. Wood and Fiber Science 2010; 42: 490-510.

Ross RJ, Willits SW, Segen WN, Black T, Brashaw B, Pellerin RF. A stress wave based approach to nde of logs for assessing potential veneer quality. Part 1 . Small-diameter ponderosa pine. Forest Products Journal 1999; 49(11/12): 60-62.

Rowell RM. Handbook of wood chemistry and wood composites. Boca Raton: CRC Press; 2005.

Suchsland O, Jankowsky IPA. Produção de lâminas de madeira por desenrolamento. IPEF 1978; 33: 1-9.

Tanritanir E, Hiziroglu S, As N. Effect of steaming time on surface roughness of beech veneer. Building and Environment 2006; 41(11): 1294-1497. http://dx.doi. org/10.1016/j.buildenv.2005.05.038

Vidaurre GB. Caracterização anatômica, química e físico-mecânica da madeira de paricá (Schizolobium amazonicum) para produção de energia e polpa celulósica [tese]. Viçosa: Departamento de Engenharia Florestal, Universidade Federal de Viçosa; 2010.

Wang J, Biernacki JM, Lam F. Nondestructive evaluation of veneer quality using acoustic wave measurements. Wood Science and Technology 2001; 34: 505-516. http:// dx.doi.org/10.1007/s002260000069 